\section{EDUCAÇ̃̃̃O}

V.10 • N.2 • Número Temático - 2020

ISSN Digital: 2316-3828

ISSN Impresso: 2316-333X

DOI: 10.17564/2316-3828.2020v10n2p25-36
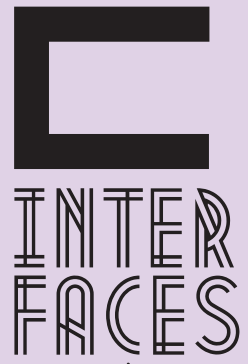

CIENTÍFICAS

\title{
LITERATURA DIGITAL E CONVERGENNCIAS NA ESCOLA: O QUE EXPRESSAM AS CRIANÇAS INTERAGINDO COM NARRATIVAS NOS DISPOSITIVOS MÓVEIS?
}

DIGTAL LITERATURE AND CONVERGENCES IN SCHOOL: WHAT DO CHLLDREN EXPRESS WHEN INTERACTING NARRATIVES ON MOBILE DEVICES?

\section{LITERATURA Y CONVERGENCIAS DIGITALES EN LA ESCUELA: ¿QUÉEXPRESAN LOS NIÑOS INTERACTUANDO COM LAS NARRATIVAS EN LOS DISPOSITIVOS MÓVILES?}

Camila Gomes Santos da Silva Vinicius Silva Santos ${ }^{2}$

\section{RESUMO}

Este artigo tem como objetivo descrever as principais expressões utilizadas pelas crianças sobre a experiência de imersão com narrativas digitais vivenciadas numa oficina de literatura digital, de modo a revelar as concepções das crianças sobre as interações estabelecidas com as narrativas literárias digitais, suas possibilidades de criação, colaboração e aprendizagens com essas linguagens. Este trabalho faz parte dos estudos e pesquisas realizados no Grupo de Pesquisa de Formação de Professores, Educação e Contemporaneidade- FORPEC/ UNEB/CNPq. A pesquisa foi realizada com a participação de 20 crianças com idade entre 5 e 6 anos. A metodologia da pesquisa utilizada é de natureza qualitativa, inspirada na pesquisa multirreferencial, proposta por Macedo $(2010,2015)$. Os instrumentos de coleta de informações foram: roda de conversa, observação e filmagem etnográfica. Os resultados deste estudo dão destaque as narrativas digitais de comunicação como sendo potencializadoras das aprendizagens na formação de leitores infantis por meio das expressões utilizadas pelas crianças durante a experiência de imersão com os enredos literários de natureza digital na escola.

\section{PALAVRAS-CHAVE}

Literatura Digital. Dispositivos. Crianças. Escola. 
This article aims to describe the main expressions used by children about the experience of immersion with digital narratives lived in a digital literature workshop, in order to reveal the children's conceptions about the interactions established with digital literary narratives, their creation possibilities, collaboration and learning with these languages. This work is part of the studies and research carried out in the Teacher Training Research Group on Teacher Education, Education and Contemporary - FORPEC / UNEB / CNPq. The research was carried out with the participation of 20 children aged between 05 and 06 years. The research methodology used is of a qualitative nature, inspired by the multi-referential research, proposed by Macedo $(2010,2015)$. The instruments for collecting information were: conversation wheel, observation and ethnographic filming. The results of this study offer prominence as digital narratives of communication, as enhancing learning in the training of children's readers through expressions used by children during the experience of immersion with literary plots of digital nature at school.

\section{KEYWORDS}

Digital Literature; Devices; Children; School.

\section{RESUMEN}

Este artículo tiene como objetivo describir las principales expresiones utilizadas por los niños sobre la experiencia de inmersión con narrativas digitales vividas en un taller de literatura digital, con el fin de revelar las concepciones de los niños sobre las interacciones establecidas con las narrativas literarias digitales, sus posibilidades de creación, colaboración y aprendizaje con estos idiomas Este trabajo forma parte de los estudios e investigaciones realizados en el Grupo de Investigación en Formación Docente, Educación y Contemporánea - FORPEC / UNEB / CNPq. La investigación se realizó con la participación de 20 niños de edades comprendidas entre 05 y 06 años. La metodología de investigación utilizada es de naturaleza cualitativa, inspirada en la investigación multirreferencial, propuesta por Macedo $(2010,2015)$. Los instrumentos para recopilar información fueron: rueda de conversación, observación y filmación etnográfica. Los resultados de este estudio ofrecen prominencia como narrativas digitales de comunicación, como una mejora del aprendizaje en la formación de lectores infantiles a través de expresiones utilizadas por los niños durante la experiencia de inmersión en tramas literarias de naturaleza digital en la escuela. 


\section{PALABRAS CLAVE}

literatura digital; Dispositivos; Niños; Escuela.

\section{INTRODUCÇÃO}

A utilização de dispositivos digitais por crianças é um fenômeno contemporâneo que demarca a produção cultural humana dos últimos vinte anos e envolve a imersão em diferentes narrativas digitais com aparelhos eletrônicos, a exemplo dos smartphones e tablets que redirecionam os modos de apropriação de informações, apresentam diferentes formas de interação e comunicação e possibilitam outras sensibilidades criativas.

Este estudo tem como ponto de partida o contexto de transformações das Tecnologias da Informação e da Comunicação (TDIC) e desenvolvimento exponencial de dispositivos eletrônicos e suas influências nos processos de socialização humana, com ênfase nos atores sociais infantis. Nota-se que as crianças são envolvidas cada vez mais cedo por telas interativas e processos de linguagem nesses ambientes. Possuem uma postura de manipulação de informações e também são produtoras de conteúdos nas redes sociais.

O objetivo deste artigo é descrever as principais expressões utilizadas pelas crianças sobre a experiência de imersão com narrativas digitais vivenciadas numa oficina de literatura digital, de modo a revelar as concepções das crianças sobre as interações estabelecidas com as narrativas literárias digitais, suas possibilidades de criação, colaboração e aprendizagens com essas linguagens.

Esse trabalho faz parte dos estudos e pesquisas realizados no Grupo de Pesquisa de Formação de Professores, Educação e Contemporaneidade - FORPEC/UNEB/CNPq da Universidade do Estado da Bahia - UNEB/Campus VIII, contemplando o projeto intitulado: Interação e Aprendizagem de Crianças com narrativas e conteúdos digitais na faixa-etária entre 2 e 12 anos de idade, levando em consideração os produtos ofertados pela indústria midiática e sua relação com a cada extrato infantil.

\section{CAMINHOS METODOLÓGICOS DA EXPERIÊNCIA}

Este estudo se inspira na abordagem qualitativa de pesquisa, de cunho multirreferencial em função do objeto e dos caminhos que serão percorridos durante a aproximação com os participantes do estudo, e se inspira na pesquisa multirreferencial, proposta por Macedo $(2010,2015)$ como caminho para revelar uma implicação do pesquisador numa experiência implicada com o fazer investigativo. Optou-se pelo planejamento e execução de uma oficina intitulada: Ciberliteratura Digital: as mídias também contam histórias!

0 principal intuito foi proporcionar às crianças o contato e imersão com diferentes narrativas literárias digitais, levando em consideração o não acesso aos dispositivos tecnológicos na escola. 
Nessa experiência, foram propostas atividades digitais a partir da exploração de aplicativos em dispositivos digitais móveis, especialmente, do aplicativo "Crianceiras", contendo poemas musicados e animados do Poeta Manoel de Barros.

A experiência foi realizada com a participação de 20 crianças $^{3}$ com idade de 5 e 6 anos, residentes no município de Paulo Afonso, no Estado da Bahia, em fase de desenvolvimento da segunda infância e regularmente matriculadas em uma escola da rede municipal. Foram criados dois grupos de interação, com o intuído de envolver um número maior de crianças, mas também primando pelas experiências e expressões resultantes das mediações com os dispositivos digitais no decorrer da oficina.

Nesse espaço, foram vivenciadas experiências de aprendizagens por meio da utilização de dispositivos tecnológicos como tablets e smartphones, além de imersão a vídeo-poesia e trailer book exposto a partir de recursos audiovisuais. Não obstante, entre as narrativas literárias digitais exploradas, foram propostos momentos de socialização por meio de rodas de conversa interativas, com o intuito de escutar as percepções das crianças sobre as narrativas e as significações das mesmas, acerca da vivência literária digital proposta.

\section{NARRATIVAS DIGITAIS, INTERAÇ̃̃O E CONVERGÊNCIA NA ESCOLA?}

O crescente uso de tecnologias digitais e redes interativas de informação e comunicação por crianças e adolescentes apresenta-se como uma profunda revolução nas relações com o saber, ao ampliar as possibilidades de acesso à informação e a plataformas virtuais potencializadoras das aprendizagens, também desenvolvimento de competências e habilidades significativas aos processos indenitários, autônomos e cognitivos dos leitores infantis contemporâneos. Nesse contexto, Lévy (1999) afirma que as tecnologias digitais prolongam determinadas capacidades cognitivas humanas, entre elas a imaginação, memória e percepção.

Assim sendo, a partir da convergência midiática abordadas por Jenkins (2009), onde as mídias tradicionais e mídias digitais se entrelaçam em perspectiva transmidiática, as narrativas de caráter ficcional ou não, apresentam-se em diferentes meios, contextos e interfaces virtuais ao alcance das crianças, devido à familiaridade que elas possuem com os instrumentos midiáticos e dispositivos tecnológicos móveis.

Deste modo, as narrativas tradicionais e contemporâneas assumem plataformas transmidiáticas, nas quais as histórias ou experiências se desenvolvem por meio de recursos tecnológicos em caráter complementar, ao ampliar as narrativas literárias tradicionais entrelaçadas a aspectos audiovisuais propícios das TDIC. Ademais, ao expandir o poder de contar histórias, somos capazes de penetrá-las em nossa imaginação e tocar outros corações.

Segundo Santos, Santos e Nunes (2018, p. 11) a imersão de crianças às tecnologias é um fenômeno corriqueiro e difundido por meio da cultura do acesso aos dispositivos em rede, alterando não só as dimensões comunicacionais, como também as dimensões corporais e subjetivas dos atores sociais infantis, fazendo surgir experiências de interação, colaboração que superam as relações mecânicas

3 No trabalho, os nomes utilizados para se referir às crianças são fictícios às crianças, respeitando o sigilo dos mesmos.

Interfaces Científicas • Aracaju • V.10 • N.2 • p. 25 - 36 • Número Temático - 2020 
observadas no interior das escolas; ao contrário, surgem “[...] espaços de interação do ciberespaço. Inquestionáveis currículos vivos que comportam ação e interação. Nesses espaços são gerenciadas incertezas, comunicação, criatividade e conexões”.

Para Chartier (2002) os novos meios de comunicação se apresentam como fortalecimento da cultura textual, de modo que o sujeito leitor por meio da tela tem a possibilidade de acesso a informações e comunicações que articulam e agregam textos, imagens e sons. Em suas análises, o autor afirma que as transmissões eletrônicas textuais transformam a noção de contexto ao substituir a contiguidade física textual, onde o leitor pode tornar-se um dos possíveis autores de textos multiautorais ou criador de novos textos constituídos por fragmentos de outros, além de intervir a qualquer momento para modificá-lo ou reescrevê-lo, devido ao amplo acesso de sons e imagens em um único dispositivo.

Segundo Kirchof (2009), a literatura hipertextual baseia-se em recursos não-lineares por meio de links e hiperlinks, enquanto a literatura hipermidiática baseia-se em recursos multimidiáticos ao agregar múltiplas linguagens.

Neste direcionamento, segundo Fernandes (2009) as crianças na contemporaneidade já nascem em um contexto de práticas de leituras diversificadas e entremeadas, no qual a imagem audiovisual faz parte. Sendo assim, a autora afirma que na atualidade o ato de aprender a ler também inclui a leitura da mídia e da literatura estética audiovisual, de modo a transformar as informações em conhecimentos e aprendizagens significativas ao desenvolvimento cognitivo infantil.

Não obstante, ao corroborar com Santaella, Fernandes (2009) afirma que desde o surgimento de jornais, revistas e livros ilustrados, a leitura passou a não se restringir ao ato de decifrar letras, no qual expande a concepção de leitura ao ato de decifrar e compreender outros códigos semióticos, como a iconografia.

Greenfield (1988) afirma que aprender a decodificar os símbolos do cinema e da televisão é um ato semelhante ao de ler e escrever, onde, entender o cinema e a televisão depende do conhecimento de código simbólico do meio. Por conseguinte, tendo em vista as inúmeras histórias contadas e recontadas por meio da mídia, a criança desde tenra idade estabelece contato com diferentes enredos narratológicos advindas da TV, smartphones, tablets e demais dispositivos tecnológicos, de modo a potencializar o contato da criança a amplas formas de linguagens textuais, auditivas e imagéticas.

Ademais, as narrativas literárias estão cada vez mais transformadas e propiciadas por meio digital, a exemplo são os trailers books, vídeo-livros e áudio-livros presentes na contemporaneidade. Segundo Greenfield (1988) as crianças que assistem à história em versão televisada usam mais a ação ao lembrar posteriormente da história apresentada. Não obstante, a criança imersiva em uma convergência midiática no tempo presente, constitui-se em um leitor de múltiplas linguagens, modos, contextos e desejos.

Nesse sentido, Santaella (2004) aborda três concepções de leitores: O leitor contemplativo, o leitor fragmentado e o leitor virtual. A primeira concepção de leitor, o contemplativo, refere-se ao leitor do livro impresso e de imagens fixas ou expositivas, onde o leitor executa a contemplação e ruminação por leitura de signos em objetos móveis e manuseáveis, como o livro, pinturas, gravuras, mapas e partituras, no qual pode-se voltar as páginas repetidas vezes, suspendendo-as por meio da imaginação para a meditação de um leitor concentrado e solidário. 
O segundo leitor conceituado pela autora, o leitor fragmentado, é aquele ajustado aos novos ritmos de atenção e velocidade de transformação do fixo ao móvel, fruto de exponenciais estímulos do contexto urbano, cercado por múltiplas imagens e distrações fugazes, onde a percepção tornou-se instável. Sendo assim, o leitor fragmentado apresenta-se como um leitor de linguagens efêmeras, misturadas e hibridas. Por conseguinte, o terceiro leitor abordado por Santaella (2004) é o leitor virtual, advindo das tecnologias digitais de informação e comunicação. Segundo a autora, o leitor virtual é aquele conectado a tela, que faz a leitura entorno da união de textos a-sequenciais e fragmentos de informações, onde cria e experiencia a interação do potencial dialógico da hipermídia, em processos comunicativos multilineares e labirínticos. Nessa concepção de leitor, Lúcia Santaella (2004, p. 34) explicita que:

[...] a navegação interativa entre nós e nexos pelos roteiros alineares do ciberespaço envolve transformações sensórias, perceptivas e cognitivas que trazem consequências também para a formação de um novo tipo de sensibilidade corporal, física e mental.

Assim sendo, a partir da concepção da autora sobre o leitor virtual, a navegação interativa do sujeito no ciberespaço possibilita a interconexão em diferentes linguagens, nuances e aprendizagens que potencializam aspectos sensoriais e cognitivos por meio da tela, no qual torna-se um leitor que atualiza, cria ou re-cria os textos da hipermídia, ao despertar o interesse e experimentação da literatura em interface virtual.

A literatura no ciberespaço amplia seus horizontes e limites, tornando-se texto verbal, audiovisual e digital de modo a atuar como estética hipertextual. Nesse direcionamento, a literatura digital atua como outras formas de narrar e poetizar. Segundo Cunha (2009) estas formas são recentes produções provenientes de matrizes numéricas, criadas por computador e vídeos. Ou seja, processos infográficos produzidos a partir de linguagens verbais, sonoras e visuais, que une a virtualidade e simulação.

Por meio da tela, o leitor apresenta-se imerso em hipertextos, constituídos por palavras, sons e múltiplas imagens animadas. Nesse contexto, Lévy (1999, p. 43) afirma que “[...] a hipertextualização multiplica as ocasiões de produção de sentido e permite enriquecer consideravelmente a leitura". Portanto, na convergência midiática ocorrida ao passar das décadas e avanço das TDIC, as crianças apresentam maiores possibilidades de imersão a enredos literários, de modo a formar leitores infantis participativos em convergência, por meio de narrativas digitais de comunicação propícias por recursos audiovisuais e instrumentos midiáticos na sociedade. Assim, pode-se afirmar que na contemporaneidade, os dispositivos também contam histórias.

\section{RELATOS E EXPRESSÕES DAS CRIANÇAS DURANTE A EXPERIÊNCIA INVESTIGATIVA}

A oficina denominada como Ciberliteratura Infantil: os dispositivos contam histórias, foi planejada e executa com o intuito de propiciar as crianças a imersão de narrativas literárias digitais a partir de dispositivos tecnológicos móveis e recursos audiovisuais, visando a formação de pequenos leitores, de modo a ampliar as possibilidades de acesso à literatura por crianças na escola. 
As atividades executadas com as crianças na oficina foram: rodas de conversa interativa, exposição do vídeo-poesia "As histórias do dedão do pé do fim do mundo", a exploração do aplicativo "Crianceiras”, ambos constituídos por poesias de Manoel de Barros $^{5}$ e a exposição do trailer book "como apanhar uma estrela”. A oficina deu-se início com um breve diálogo com as crianças, de modo a explorar por meio da conversa interativa, elementos que contextualizam a imersão das crianças na cultura digital.

A experiência de aprendizagem literária executada deu-se início com um breve diálogo com as crianças, de modo a explorar por meio da conversa interativa elementos que contextualizam a imersão das crianças na cultura digital, visando a utilização de recursos tecnológicos em âmbito familiar e social, além de constituir um contato inicial e envolvimento com as crianças de modo a ser aceito no grupo, atuando como mediadora de atividades a serem desenvolvidas durante a oficina.

Nesse direcionamento, ao questionar sobre o uso do tablet ou celular, as crianças de ambos os grupos sinalizam o manuseio e utilização dos dispositivos móveis em âmbito familiar, de modo a sinalizar o processo de digitalização da cultura infantil. Em seguida, ao apresentar as atividades a serem desenvolvidas ao longo da oficina, foi perguntado as crianças quais as narrativas que as mesmas possuem acesso em casa. Ao responder o que foi solicitado, as crianças relatam ter contato com contos clássicos e narrativas transmidiáticas referentes aos desenhos animados e enredos fílmicos. Sendo assim, as principais narrativas apresentadas por elas foram: Rapunzel, Elza (personagem do Frozen), Tiranossauro Rex, Homem Aranha, Branca de Neve e Cinderela.

Ao observar o manuseio dos dispositivos digitais por parte das crianças em duplas, foi notório a familiaridade que possuem com as funções dos dispositivos. Percorrem os diversos espaços e funcionalidades do aplicativo, trocaram o domínio dos aparelhos com os colegas e foram descobrindo os links e hiperlinks. Cada descoberta foi celebrada em expressões como "olha”, "que lindo", "massa”, "passa o dedo aqui", "adorei as cores” e muitas outras. Algumas crianças enfatizam o acesso às histórias por meio de dispositivos tecnológicos e recursos audiovisuais. Isso é notório no relato de Bia, quando verbaliza a seguinte frase: “Eu assisto Branca de Neve no meu tablet e na televisão". Ou no questionamento de Gabriel, quando traz para o diálogo a seguinte pergunta: "Tia, você já assistiu à história do pé de feijão?” Referindo-se ao conto clássico “João e o pé de feijão”.

Não obstante, no decorrer da roda de conversa, um dos alunos que sinalizou anteriormente gostar da "história do homem aranha" após breve diálogo com o colega sentado ao lado, levanta-se e começa a fazer gestos parecidos com o personagem, tais como "jogar a teia" e pular. Para Greenfield (1988) o movimento visual de narrativas televisadas auxilia na aprendizagem ao tornar as informações por meio de ações mais fáceis de serem lembradas. Segundo a autora, enquanto no livro (embora descri-

4 Projeto idealizado por Márcio de Camillo que, transformou em músicas as poesias de Manoel de Barros, por meio do aplicativo "Crianceiras", com o intuito de incentivar o contato de crianças com a literatura. 0 aplicativo está disponível nas plataformas Google Play (Android) e Apple Store (IOS).

5 Poeta brasileiro, nascido em Cuiabá-MT, conhecido por trazer em suas narrativas elementos do primitivo relacionados à natureza e realidade que o cercava. Autor de obras conhecidas como: Compêndio Para Uso dos Pássaros” (1961), "Gramática Expositiva do Chão” (1969), “Matéria de Poesia” (1974), “Livro Sobre Nada” (1996), “Retrato do Artista Quando Coisa” (1998) e "Portas de Pedro Vieira” (2013). Recebeu o Prêmio Jabuti de Poesia duas vezes, em 1990 e 2002, com as obras “O guardador de águas” (1989) e “O fazedor de amanhecer” (2001). 
tas na narração) as ações apresentam-se implícitas, na televisão ou cinema as ações apresentam-se visualmente explícitas, de modo que quando a criança é lembrada da história em versão televisada, posteriormente também utiliza-se de ações para retratá-la.

Além disso, os movimentos visuais da televisão ou cinema atraem a atenção da criança e imersão delas, no contexto ou narrativa exposta na tela. Nesse sentido, no decorrer da exposição do vídeo-poesia foi notório o envolvimento de grande parte das crianças observadas. Na ocasião, algumas crianças buscavam se aproximar da tela para melhor visualização, outras apontavam para a tela, enquanto algumas apresentavam-se atentas e envolvidas com os olhos fixados e bocas entreabertas. Nesse direcionamento, Levin (2007, p. 34) enfatiza que "o espelho cultural da televisão liga a criança com uma rede de ideias, sentidos, imagens e sensações afetivas rápidas, fragmentárias e simultâneas".

Nesse contexto, durante a exposição do vídeo-poesia "A história do dedão do pé do fim do mundo" observaram-se algumas expressões, como risadas estimuladas por risos presentes na sonorização da narrativa, olhos atentos a tela, crianças imitando o movimento do desenho ilustrativo do poema com a cabeça, sorriso explícito e verbalização de algumas palavras ou pequenas frases tais como: "uau", “eita, olha!”, “quantas mãos...”. Isso explica-se a partir das concepções de Vigotsky (2007) sobre o desenvolvimento da percepção e atenção da criança.

Para o autor, a criança inicia o processo de percepção do mundo não somente por meio dos olhos, mas também por meio da fala. Assim, a linguagem e percepção estão ligadas, pois, de acordo com Vigotsky (2007) a linguagem apresenta um grande papel no processo de percepção infantil, de modo que a partir de tendências implícitas naturais do processo de percepção visual, elementos independentes em um campo visual apresentam-se simultaneamente com a linguagem.

Entre os relatos das crianças, apresentam-se elementos fragmentados ao explicitar: "Eu gostei do passarinho"; "Eu gostei mais do sol”; "não, eu gostei mais quando ele estava com um monte de mãos”; "E eu gostei do dedão que vira mundo". Por conseguinte, entre o diálogo sobre os aspectos do vídeo-poesia, João traz uma contribuição interessante a respeito dos aspectos narratológicos do poema: "Eu gostei da parte que dava para fazer brinquedo com a letra", ao ser questionado: "E como a gente pode fazer brinquedo com a letra?” uma criança ao fundo responde: “Montando...”, ele continua: “Porque quando a gente faz palavra, a gente pode brincar". As trocas e falas entre as crianças também foram notadas pelo nível de implicação com a proposta.

É necessário destacar que as crianças participantes fizeram uso do aplicativo sem apresentar dificuldades, de forma autônoma e interativa a partir de escolhas próprias e não sequências, partindo da concepção de Chartier (1994), quando o autor enfatiza que as tecnologias digitais apresentam-se como uma revolução da escrita, pois, o texto em tela apresenta múltiplas formas e possibilidades de leituras.

Não obstante, no decorrer da exploração dos espaços de aprendizagens interativos do aplicativo Crianceiras, foi observado que a maioria das crianças ao tratar-se dos espaços que apresentam os poemas musicados ou em linguagem escrita, ficou por maior tempo explorando as poesias em vídeos, de modo a serem atraídas por narrativas literárias de estética audiovisual, revelando-se assim, como pequenos leitores fragmentados, atraídos e envolvidos por estímulos de múltiplas imagens hibridas (SANTAELLA, 2004).

Neste direcionamento, Greenfield (1988) apresenta estudos desenvolvidos a partir do uso de filmes e programas educativos da TV como potencial de apoio a leitura, no qual a autora ressalta que os 
filmes, ao estimular a compreensão e memorização de histórias, despertam o desejo da criança em fazer leituras semelhantes à história audiovisual apresentada.

Esta concepção evidencia-se com duas crianças pertencentes a grupos distintos da pesquisa. No qual, observando o manuseio de Maria ao longo da atividade proposta, foi presenciado o fato de que, após visualizar o vídeo-poesia "Sombra Boa", a criança ao acessar o espaço Poesia do Crianceiras vai em imediato a procura do mesmo poema em versão textual. Isso é notório também com Pedro. Pois, ao perguntar sobre os poemas que a criança mais gostou, ele relata ter gostado do vídeo do "caranguejo", referindo-se ao poema "Se Achante".

Ademais, ao manusear os poemas em texto interativo, a criança me solicita a leitura dos poemas. Logo após, foi ela foi questionada: “E desses poemas? Qual você mais gostou?” Em imediato, a criança aponta para o poema Se Achante e enfatiza: “Desse que tem o caranguejo também”. A partir desse fato observado, cabe pontuar que as tecnologias digitais e os livros podem atuar em conjunto no processo de imersão da criança em narrativas literárias, não precisando serem considerados como meios competitivos de comunicação e informação.

No decorrer do manuseio dos dispositivos móveis e exploração das narrativas literárias no aplicativo, foi notória a empolgação, curiosidade e envolvimento das crianças, de modo a agregar sentidos às atividades em interfaces digitais propostas ao longo da realização da oficina. Ademais, as crianças demonstraram o prazer e interatividade por meio dos enredos lúdicos narratológicos em contato, no qual obteve-se interesse na continuidade da exploração do aplicativo Crianceiras em âmbito familiar. Esta interpretação justifica-se por meio do relato de Davi, pois, durante a visualização de um dos poemas musicados do app, a criança me questiona: "Para achar esse aplicativo a gente pesquisa o nome Crianceiras é? Vou pedir para minha mãe baixar no meu celular".

Ao finalizar a oficina foi perguntado às crianças sobre o que acharam das histórias utilizadas durante a experiência de aprendizagem proposta. As crianças verbalizaram: "Eu gostei de todas!”; “Eu gostei das histórias do tablet”; “foi legal!”. Percebe-se que a história possui uma relevância inconteste, sobremaneira quando expressam o desejo pela narrativa estando estimuladas pelos usos de mecanismos imagéticos, sonoros e visuais, possíveis com os dispositivos digitais que, dão novos sentidos à experiência. Por último, envolvidos com trailer book “Como apanhar uma estrela”, as crianças levantam-se e começam a dançar, pular, dar risadas e balançar a cabeça a partir da sonorização e ações expostas na tela.

\section{CONSIDERAÇÕES FINAIS}

Os achados da pesquisa foram sendo sistematizados por meio de intensas observações e questionamentos acerca do objeto de pesquisa investigado e vivenciado com as crianças. 0 uso dos dispositivos para mediar a imersão infantil com as narrativas literárias tornou a experiência rica, sendo possível notar isso, nas expressões, falas e corpos das crianças participantes.

Além disso, por meio da imersão em narrativas literárias e utilização de dispositivos móveis em duplas ao longo da oficina, as crianças apresentaram-se envolvidas, participativas e agiram em coletivo 
ao compartilhar o dispositivo móvel com o colega, partilhar as descobertas dos espaços interativos do aplicativo explorado com as demais duplas participantes da experiência ou chamá-los para registrar o momento vivenciado por meio de fotos em grupo.

Os usos dos dispositivos para mediar a imersão infantil com as narrativas literárias tornaram a experiência rica, sendo possível notar isso nas expressões, falas e corpos das crianças participantes. Dessa maneira, as crianças demonstram por meio de expressões faciais e corporais a empolgação e prazer ao manusear as narrativas literárias em plataformas digitais, além de enfatizar por meio da fala ao longo da experiência, pequenas frases ou breves diálogos entre seus pares que evidenciam o interesse delas pela atividade desenvolvida.

Não obstante, por meio das narrativas literárias digitais as crianças exploram competências visuo-espaciais, de modo a interligar os enredos narratológicos dos vídeo-poemas a aspectos vivenciais, quer seja em âmbito familiar ou situações de aprendizagens presentes na rotina escolar, tais como a constituição de palavras, sons e imagens, no qual a criança começa a questionar aspectos relevantes das narrativas em paralelo aos elementos constituintes do mundo real.

Ainda nesse direcionamento, por meio das influências das narrativas digitais na aprendizagem e formação de leitores infantis, nota-se que por meio do contato com as narrativas literárias digitais, as crianças desenvolvem o processo de linguagem, agregando novos e significativos conhecimentos aos já apreendidos, além de percepções em leitura de aspectos estéticos audiovisuais presentes nos enredos narratológicos digitais em contato.

Por fim, cabe destacar que no período de finalização da oficina literária digital algumas crianças apresentam o desejo de continuar a manusear as obras literárias musicadas em âmbito familiar, tornando a experiência de aprendizagem vivida durante o plano de ações proposto, significativa ao processo de aprendizagem e formativo das crianças. É interessante registrar que, ações como estas, envolvem um planejamento, orientação e abertura para o imprevisível, ao passo que potencializam o protagonismo infantil com as culturas digitais, criando espaços de colaboração, convivência, trocas, sensações e partilhas.

\section{REFERÊNCIAS}

CHARTIER, R. As revoluções da leitura no ocidente. In: ABREU, M. (org.). Leitura, história e história da leitura. São Paulo: Mercado de Letras, 2002. p. 19-31.

CUNHA, Maria Zilda da. A tessitura dos signos contemporâneos: novos olhares para a literatura infantil e juvenil. São Paulo: Editora Humanitas; Paulinas, 2009.

FERNANDES, Adriana Hoffmann. Infância e cultura: o que narram as crianças na contemporaneidade? Brasil, 2009. 241 f. Tese (Doutorado em Educação) - Programa de Pósgraduação em Educação, Universidade do Estado do Rio de Janeiro, Rio de Janeiro, 2009. 
GREENFIELD, Patrícia Marks. 0 desenvolvimento do raciocínio na era da eletrônica: os efeitos da TV, computadores e videogames. Tradução de Cecília Bonamine. São Paulo: Summus, 1988. (Novas buscas em educação; v. 32).

JENKINS, Henry. Cultura da convergência. Tradução Suzana Alexandria. 2. ed. São Paulo: Aleph, 2009.

KIRCHOF, Edgar Roberto. 0 desaparecimento do autor nas tramas da literatura digital: uma reflexão foucaultiana. Revista Signo, Santa Cruz do Sul, v. 34, n. 56, p. 47-63. jan./ jun. 2009. Disponível em: https://online.unisc.br/seer/index.php/signo/article/view/962. Acesso em: 7 ago. 2020.

LEVIN, Esteban. Rumo a uma infância virtual? A imagem corporal sem corpo. Tradução de Ricardo Rosenbusch. Petrópolis-RJ: Vozes, 2007.

LÉVY, Pierre. Cibercultura. São Paulo: Ed. 34, 1999.

MACEDO, Roberto Sidnei. Etnopesquisa crítica/Etnopesquisa-formação. Brasília: Líber Livro, 2010.

MACEDO, Roberto Sidnei. Pesquisar a experiência: compreender/mediar saberes experienciais.

Curitiba- PR: CRV, 2015.

SANTAELLA, Lúcia. Navegar no ciberespaço: o perfil cognitivo do leitor imersivo. São Paulo: Paulus, 2004.

SANTOS, Vinicius Silva; SANTOS, Jacques Fernandes; NUNES, Andrea. Karla. Ferreira Nunes Tecnologias Digitas de Informação e Comunicação - TDIC e Currículo Escolar: reflexões sobre a aprendizagem na cultura juvenil contemporânea. In: XII Colóquio Internacional Educação e Contemporaneidade. São Cristóvão, 2018.

VIGOTSKY, Lev. Semenovich. A formação Social da Mente: o desenvolvimento dos processos psicológicos superiores. COLE, Michael et al (org.). Tradução José Cipolla Neto, Luís Silveira Menna Barreto, Solange Castro Afeche. 7. ed. São Paulo: Martins Fontes, 2007. 
1 Graduada em Pedagogia na Universidade do Estado da Bahia - UNEB/Campus VIII. Pós-Graduanda Lato Sensu em Gestão Escolar - UNIASELVI. Membro do Grupo de Pesquisa em Formação de Professores, Educação e Contemporaneidade - FORPEC (UNEB/CNPq).

E-mail: camylagomess@live.com

2 Mestre em Educação. Doutorando em Educação PPGED/ UFS. Professor da Universidade do Estado da Bahia UNEB/Campus VIII. Membro do Grupo de Pesquisa em Informática na Educação - GEPIED (UFS/CNPq) e do Grupo de Pesquisa em Formação de Professores, Educação e Contemporaneidade - FORPEC (UNEB/CNPq).

E-mail: vssantos@yahoo.com.br

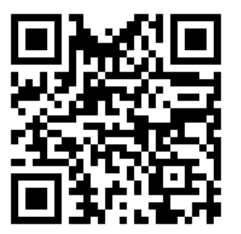

A autenticidade desse artigo pode ser conferida no site https://periodicos. set.edu.br

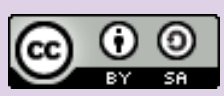

Este artigo é licenciado na modalidade acesso abertosob a Atribuição-Compartilhalgual CC BY-SA

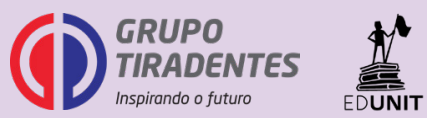

